only in those women who have unremitting dyspareunia associated with focal vulvitis for at least six months. ${ }^{5}$

Dyspareunia is a distressing symptom that may lead to serious conflicts in relationships, and those conflicts are sometimes considered to perpetuate introital pain after conventional treatment has failed. Perhaps, however, failure to examine the vulva adequately has meant that the doctor has failed to diagnose focal vulvitis in such patients.

Physician in Sexual Medicine

Alan J Riley

Wendens Ambo,

Saffron Walden,

Essex CB11 4JX

Peter Bromwich

Clinical Lecturer,

Nuffield Department of Obstetrics and Gynaecology,

John Radcliffe Hospital,

Oxford OX3 9DU

Correspondence to: Dr Riley.

1 Semmens JP, Semmens JF. Dyspareunia. Brief guide to office counselling. Medical Aspects of Human Sexuality 1974;8:85-7.

2 Kolodny RC, Masters WH, Johnson VE. Textbook of sexual medicine. 1st ed. Boston: Little Brown and Company, 1979:193-7.

3 Jeffcoate TNA. Posterior colpoperineorraphy. Am F Obstet Gynecol 1959;77:490-502.

4 Riley AJ. Vulvo-vaginal lubrication. Br f Sex Med 1986;13:277-8.

5 Peckham BM, Maki DG, Patterson JJ, Hafez GR. Focal vulvitis: a characteristic syndrome and cause of dyspareunia. Features, natural history, and management. Am $\mathcal{f}$ Obstet Gynecol $1986 ; 154: 855-64$

6 Woodruff JD, Parmley TH. Infection of minor vestibular gland. Obstet Gynecol 1983;62:609-12.

7 David I, Shapiro L, Baral J. Vulvitis circumscripta plasmacellularis. $\mathcal{J}$ Am Acad Dermatol 1983;8:413-6.

\section{Keeping up with orthopaedic epidemics}

Britain is experiencing an epidemic of surgery for fractured necks of the femur and for arthritis of the hip. The work load and its economic implications are posing a formidable challenge to the Health Service. Over 100 different types of total hip replacement are available, varying in price from just over $£ 100$ to well over $£ 1000$. There is an urgent need to compare the different prostheses, yet controlled trials that will produce statistically meaningful results will take at least 15 years. Thus, if Britain is to remain at the forefront of researching and developing implants techniques must be devised for predicting the reliability and longevity of an implant within months rather than years. Such techniques are being developed and need encouragement.

The epidemic of fractured necks of femur is overwhelming the wards allocated to the trauma service and spilling into the beds needed for both general surgery and elective orthopaedics. ${ }^{1}$ Not only is the incidence increasing with an aging population but also the risk at all ages is in itself rising. ${ }^{2}$ In elective orthopaedics a similar epidemic is occurring: in 25 years the number of total hip replacements performed in Britain has risen to 35000 a year. By 1990 the government expects the annual number of operations to have stabilised at 50000 (N Fowler, Conservative Party Conference, Bournemouth, 1986). Total knee replacements lag a few years behind-only 10000 were performed last year. American experience suggests, however, that the number will eventually rise to equal the number of hip replacements.

The traditional concepts of patients "earning" their operations is being abandoned in many units, and the days of most elderly patients taking their original joint replacement to the grave with them are now over. Young people crippled by an arthritic joint are determined, despite dire warnings, to opt for a joint replacement immediately and face the consequences of implant failure later. Yet revision rates in young patients may be as high as $25 \%$ within five years. ${ }^{3} \mathrm{~A}$ new epidemic of patients requiring joint revision is starting to make inroads into operating lists: in Oxford one in five operations to replace hips are now revisions (J Spivey, personal communication). They require on average twice as much operating time, and patients need to stay in bed longer than those having a primary implant. The results too are not nearly so certain.

The choice of implant is difficult. The criteria are simplereliability, longevity, and revisability-but the solution is not. Many different types of prosthesis-cemented or cementless-and the choice of approach to the hip multiply the possible permutations into the thousands.

Despite the cemented Charnley hip being one of the first joints to be used in large numbers 25 years ago, it still reigns supreme as the gold standard. Not one of the dozens of "newer," "better," and more expensive implants being used by many surgeons in the Health Service can match the figures obtained with the Charnley hip in proper hands. ${ }^{4}$ Nor can they ever do so. A controlled trial of several hundred implants over at least 15 years would be required to make valid comparisons. There is no prospect of a controlled trial of this size being carried out in the foreseeable future for even one of the implants on the market. Even if it was possible the results would probably be irrelevant by the time they became available. That is why we need techniques to test implants quickly.

A technique using stereo $x$ rays and bone markers has been developed that can measure the migration of implants within their bone beds to within fractions of a millimetre. ${ }^{5}$ The technique is complex but does seem to predict the lifetime of an implant. The immediate implementation of this and other complex measuring techniques will be needed if clinical research is to be used to define the design criteria of a new generation of reliable implants.

Without this research to determine efficacy cost may be the only criterion used to decide the best implant for use in the health service. This would block all improvements in implant design in Britain and would sound the death knell of the British implant industry. Conversely, encouraging this type of research would allow Britain to move ahead in the forefront of implant development while ensuring that the health service obtains the best implants in both clinical and economic terms.

Christopher Bulstrode

Clinical Reader in Orthopaedic Surgery,

Nuffield Orthopaedic Centre,

Oxford OX3 7LD

1 Duthie RB. Orthopaedic services: waiting time for outpatient appointment and inpatient treatment. Report of a working party to the Secretary of State Social Services. London: HMSO, 1981.
Boyce WJ, Vessey MP. Rising incidence of fractures of the proximal femur. Lancet 1985; 1: 150-1.

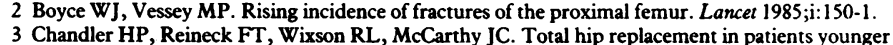
Chandler HP, Reineck FT, Wixson RL, McCarthy JC. Total hip replacement in patien
than 30 years old. A five year follow up study. F Bone foint Surg 1981;63A:1426-34. Carlsson AS, Gentz C-F, Sanzen L. Socket loosening after hip arthroplasty; radiographic observations in 241 cases up to 15 years. Acta Orthop Scand 1986;57:97-100. 5 Selvig G. Roentgenstereophotgrammetry in orthopadics. Biostereometrics 1982;361:178-85. 